there is a strong possibility that we are actually able to delineate some of the facies (e.g. bare glacial ice zone, the exposed part of superimposed ice zone, soaked and percolation zones, and dry snow zone) by tonal variations on the various multispectral scanner (MSS) bands $(4,5,6$, and 7) of Landsat images of Icelandic ice caps.

\title{
LONGITUDINAL STRESS GRADIENTS AND BASAL SHEAR STRESS OF A TEMPERATE VALLEY GLAGIER
}

\section{By RoBert BindschadleR*}

(Geophysics Program AK-5o, University of Washington, Seattle, Washington 98 195, U.S.A.)

Abstract. For the first time field data from a temperate valley glacier, the Variegated Glacier, are used to investigate the behavior of longitudinal stress gradients predicted by the relation

where

$$
\tau_{x y}\left(y_{\mathrm{b}}\right)=-f \rho g H \sin \alpha-2 G+\mathcal{T}
$$

$$
\begin{aligned}
& G=\int_{y_{\mathrm{s}}}^{y_{\mathrm{b}}} \frac{\partial \tau_{x x^{\prime}}}{\partial x} \mathrm{~d} y, \\
& T=\int_{y_{\mathrm{s}}}^{y_{\mathrm{b}}} \int_{y_{\mathrm{s}}}^{y^{\prime}} \frac{\partial^{2} \tau_{x y}}{\partial x^{2}} \mathrm{~d} y^{\prime \prime} \mathrm{d} y^{\prime},
\end{aligned}
$$

$H$ is the local depth, and $y_{\mathrm{s}}$ and $y_{\mathrm{b}}$ are the surface and bed elevations respectively. This equation is similar to one derived by Budd (1970) for plane strain-rate, to evaluate the importance of longitudinal stress gradients, but a shape factor $f$ is included to account approximately for lateral strain-rate gradients. Predictive numerical models of valley glaciers require the local base shear stress to be known as accurately as possible. It has been argued on theoretical grounds that when $T$ is averaged over distances of more than five to ten times the depth, this term is negligible. At larger averaging scales, $2 G$ can then be considered a correction to the simple geometric expression of base stress due to the presence of longitudinal stress gradients. Field data of velocity and geometry are used to evaluate the terms of Equation (I), where $\tau_{\mathrm{b}}$ and ${ }_{2} G$ are estimated as

and

$$
\tau_{\mathrm{b}}=\tau_{x y}\left(y_{\mathrm{b}}\right)=\left[\frac{(n+\mathrm{I}) U_{\mathrm{s}}}{2 A(f \rho g \sin \alpha)^{n} H^{n+\mathrm{I}}}\right]^{\mathrm{I} / n},
$$

$$
{ }_{2} G=2 H \frac{\partial}{\partial x}\left[\frac{\dot{\epsilon}_{x x}}{A}\right]^{1 / n},
$$

at intervals of roo $\mathrm{m}, U_{\mathrm{s}}$ is the measured surface center-line velocity, $A$ and $n$ are the flow-law parameters, and $\dot{\epsilon}_{x x}$ is the surface longitudinal strain-rate. The expression for $2 G$ is an approximation proposed by Budd (1970).

The precise method of distance averaging is investigated carefully. Two methods are considered: a running arithmetic mean and a digital low-pass filter. By Fourier analysis the

* Now at Versuchsanstalt für Wasserbau, Hydrologie und Glaziologie, Eidgenössische Technische Hochschule Zürich-Zentrum, CH-8og2 Zürich, Switzerland. 
former method is converted to the form of a frequency operator for comparison with the latter. Because the magnitudes of $2 G$ and $T$ depend on the wavelength of the averaging scale, it is argued that for our case the digital low-pass filter is more appropriate. This method has the additional advantage that high-frequency noise in the data, predominantly a result of measurement errors, is more effectively removed.

Both operators are applied to the data to test the ability of ${ }_{2} G$ to correct $\tau_{\mathrm{g}}$ for averages of $\frac{1}{4}, \mathrm{I}, 2,4$, and $10 \mathrm{~km}$. The average depth of the glacier is $270 \mathrm{~m}$, and $T$ is neglected in all cases. Remnant high frequency in the data arithmetically averaged interferes with any attempt to judge the effectiveness of $2 G$ as a correction. For no averaging length does the correction seem to be effective, although an averaging scale of $4 \mathrm{~km}$ appears to be the least poor. Comparison is easier with the frequency-filtered data. The agreement is best for the $4 \mathrm{~km}$ filter, where $2 G$ accounts for a large fraction of the difference between $\tau_{\mathrm{b}}$ and $\tau_{\mathrm{g}}$ over most of the filtered region. However, for large-scale filters, most data are only partially filtered. For the $4 \mathrm{~km}$ filter, these edge effects eliminate $75 \%$ of the data field.

The conclusion is that in this analysis, $2 G$ does not provide an effective means of improving the calculation of base shear stress on Variegated Glacier. This contrasts with the agreement found by Budd (1970) using Wilkes Ice Cap data. Possible explanations of this discrepancy include: errors in the field data or the shape factor may be too large to permit meaningful evaluation of a small correction term; $T$ may be significant over some regions of this glacier; the relation used to evaluate $2 G$ may be inappropriate for this valley glacier.

\title{
REFERENCE
}

Budd, W. F. 1970. The longitudinal stress and strain-rate gradients in ice masses. Fournal of Glaciology, Vol. 9, No. 55 , p. $19-27$.

\section{DISCUSSION}

W. F. BudD: Can you use your results to calculate an effective "viscosity" parameter for longitudinal stress?

R. A. Bindschadler: Yes, I foresee no difficulty.

\section{TESTING NUMERICAL MODELS OF GLAGIER FLOW}

\author{
By E. D. WAdDington \\ (Department of Geophysics and Astronomy, University of British Columbia, Vancouver, \\ British Columbia V6T I 55 , Canada)
}

Abstract. The recent glaciological literature contains a number of numerical simulations of ice-mass flow based on the mass conservation equation. Although rather complex ice masses have been modelled, there has been little discussion of the necessary tests for correct response time and amplitudes in the models. The analytical work of J. F. Nye (196o, I963[a], $\left.\mathrm{I}_{96}[\mathrm{~b}], \mathrm{I}_{96}[\mathrm{a}], \mathrm{I}_{96}[\mathrm{~b}]\right)$ on the response of a steady-state glacier to perturbations in its mass balance provides an excellent test of model dynamics. Only when properly verified can the numerical model be used to extend knowledge of glacier response to more general cases where analytical solutions are unavailable. The model in this paper is checked against Nye's calculations of response to a step increase in mass balance. It is then used to extend Nye's results by finding the time constants for diffusion parameters other than $\mathrm{o}$ and $\mathrm{I}$. 